\title{
SOBRE AS AUTORAS E OS AUTORES
}

\author{
Alessandra Fontes Carvalho da Rocha \\ Professora de Didática Especial e Prática de Ensino de Português-Literaturas da \\ Faculdade de Educação da UFRJ. Coordenadora de Área do PIBID de Português \\ - CAPES.
}

\section{Carla Cristiane Saldanha Fant}

Mestranda no Programa Profletras - Mestrado Profissional em Letras da Unioeste/Cascavel-PR; integrante do grupo de pesquisa "Ressignificações do passado na América: processos de leitura, escrita e tradução de gêneros híbridos de história e ficção - vias para a descolonização", ccsfant@gmail.com Orcid: https://orcid.org/0000-0002-4977-5806.

\section{Carlos Magno Gomes}

Prof. Dr. de teoria literária da UFS. Pesquisador Produtividade do CNPq vinculado ao Profletras da Unidade de Itabaiana e ao PPGL. E-mail: calmag@bol.com.br.

\section{Christina Ramalho}

Professora-Adjunta 4 do Curso de Letras da Universidade Federal de Sergipe, campus Itabaiana. Doutora em Letras pela UFRJ (2004), com PósDoutoramento em Estudos Cabo-Verdianos (USP/FAPESP, 2012) e Estudos Épicos (Université Clermont-Auvergne, 2017). Atua no Programa de PósGraduação em Letras (Estudos Literários) e no Programa de Mestrado Profissional em Letras (PROFLETRAS/ITABAIANA), da Universidade Federal de Sergipe.

\section{Cristian Javier Lopez}

Doutor pela UVIGO/Espanha em cotutela com a Unioeste/Cascavel-PR/Brasil; integrante do Grupo de pesquisa "Ressignificações do passado na América: processos de leitura, escrita e tradução de gêneros híbridos de história e ficção 
- vias para a descolonização", cj_lopez2@hotmail.com Orcid: http://orcid.org/0000-0002-7391-8395.

\section{Diego Domingues}

Professor de Português na Rede Municipal de Duque de Caxias/RJ. Professor supervisor do Pibid de Português na Escola Municipal Nísia Vilela Fernandes CAPES.

\section{Edneia de Oliveira Alves}

Letras - Inglês / Português. Mestre em Psicologia Social. Doutora em Psicologia Social. Professora de Libras na Universidade Federal da Paraíba (UFPB). edneiaalvesufpb@gmail.com.

\section{Francyllayans Karla da Silva Fernandes}

Pedagogia. Letras-Libras. Psicologia. Mestranda em Educação pela Universidade Federal da Paraíba (UFPB). francyllayans@gmail.com.

\section{Gilmei Francisco Fleck}

Pós-doutor em Literatura Comparada e Tradução pela Uvigo/Vigo-Espanha; Doutor em Letras pela Unesp/Assis-SP. Líder do Grupo de pesquisa "Ressignificações do passado na América: processos de leitura, escrita e tradução de gêneros híbridos de história e ficção - vias para a descolonização"; chicofleck@yahoo.com.br Orcid: https://orcid.org/0000-0002-4228-2566.

\section{Jailma dos Santos Pedreira Moreira}

Professora Dra. do curso de Letras e do Programa de pós-graduação em Critica Cultural da UNEB-Campus II. Integrante do grupo de pesquisa Lingua(gem) e Crítica Cultural Email: jailmapedreira@uol.com.br. 


\section{Joice Mariane Andrade Cruz Borba}

Mestranda em Letras pelo PROFLETRAS na UPE/Campus Mata Norte. E-mail: joice.mariane@yahoo.com.br.

\section{José Jacinto dos Santos Filho}

Doutor em Educação pela UFPE. Professor Adjunto da Universidade de Pernambuco - UPE/Campus Mata Norte. E-mail: jacinto.santos@upe.br

\section{José Wellington Dias Soares}

Professor Adjunto do curso de Letras da FECLESC (Faculdade de Educação, Ciências e Letras do Sertão Central) da UECE (Universidade Estadual do Ceará). Quixadá-Ceará. E-mail: wellington.soares@uece.br

\section{Joseneide Santos de Jesus}

Mestra em Letras pelo Profletras da Unidade de Itabaiana. Professora da Rede Estadual da Bahia. Bolsista CAPES (2017-2019). E-mail: josynj.21@gmail.com

\section{Jussara Figueiredo Gomes}

Mestra em Crítica Cultural pela Universidade do Estado da Bahia - UNEB. Email: jussarafgomes@hotmail.com

\section{Luiz Guilherme Ribeiro Barbosa}

Professor de Português e Literaturas de Língua Portuguesa no Colégio Pedro II. Professor supervisor do Pibid de Português no Colégio Pedro II - CAPES

\section{Marcio Santos da Conceição}

Doutorando do Programa de Pós Graduação em Crítica Cultural da UNEB, sob a orientação da professora Dra. Maria de Fátima Berenice da Cruz- Campus II, Mestre em Crítica Cultural pela UNEB, Campus II - Alagoinhas, membro do grupo de Pesquisa GEREl (Grupo de Estudos em Resiliência, Educação e 
Linguagens) e professor da Faculdade Santíssimo Sacramento - Alagoinhas. Email: msconceicao18@gmail.com

\section{Marcos Scheffel}

Professor de Didática Especial e Prática de Ensino de Português-Literaturas da Faculdade de Educação da UFRJ. Coordenadora de Área do PIBID de Português - CAPES

\section{Marianne Rossi Stumpf}

Tecnologia em Informática. Educação dos Surdos. Doutora em Informática na Educação. Professora Adjunta na Universidade Federal de Santa Catariana (UFSC). stumpfmarianne@gmail.com

\section{Maria de Fátima Berenice da Cruz}

Professora do Programa de Pós-Graduação em Crítica Cultural (UNEB). Líder do Grupo de pesquisa GEREL/CNPq. E-mail. mfcruz@uneb.br

\section{Neide Luzia de Rezende}

professora do Departamento de Educação da Universidade de São Paulo e tradutora de Annie Rouxel

\section{Sanadia Gama dos Santos}

Doutora em Letras pela Universidade Estadual de Maringá (UEM). Mestra em Letras pela Universidade Federal de Sergipe. Professora da Universidade Estadual de Alagoas (UNEAL). E-mail: sanadiasantos@yahoo.com.br

\section{Sandra Freitas de Carvalho Cruz}

Mestra em crítica Cultural pelo Programa de pós-graduação em Critica Cultural da UNEB-Campus II. Integrante do grupo de pesquisa Lingua(gem) e Crítica Cultural. Email: sanuneb@hotmail.com 


\section{Sandy Karelly Freitas Falcão}

Mestranda em História e Letras pela UECE - Universidade Estadual do Ceará. E-mail: sandyfalcao@gmail.com

\section{Vania Maria Ferreira Vasconcelos}

Doutora em Literatura Contemporânea pela UNB, membro do GT Mulher na Literatura, da ANPOLL e do Grupo de Pesquisa Vozes Femininas, professora do Curso de Letras da UNILAB - Universidade da Integração Internacional da Lusofonia Afro-Brasileira e do Mestrado Interdisciplinar em História e Letras MIHL, da UECE - Universidade Estadual do Ceará. E-mail: vaniavas@gmail.com 